\title{
The Interaction of Bovine Factor VIII with Human Platelets
}

\author{
Edward P. KmbY and Davm C. B. Mills \\ From the Department of Biochemistry and the Specialized Center for \\ Thrombosis Research, Temple University Health Sciences Center, \\ Philadelphia, Pennsylvania 19140
}

A B S T R A C T Treatment of human platelets with purified bovine Factor VIII caused three types of aggregation: (a) primary agglutination; $(b)$ secondary aggregation involving the platelet release reaction; and $(c)$ super-aggregation, in which the platelets were gathered into only a few large clumps. Removal of calcium ions or treatment with p-hydroxymercuriphenyl sulfonate blocked the release reaction, but not primary agglutination or super-aggregation. Platelets treated with formalin were not aggregated by ADP, thrombin, or collagen, but were agglutinated by bovine Factor VIII, although they did not show super-aggregation. Formalin-treated platelets were agglutinated by phytohemagglutinin $\mathrm{P}$ less extensively and less rapidly than by bovine Factor VIII. Treatment of platelets and Factor VIII with neuraminidase released 60 and $53 \%$, respectively, of the sialic acid residues without affecting the agglutination reaction or the procoagulant activity of the Factor VIII. Agglutination was inhibited by high salt concentrations, dextran sulfate, and heparin. During agglutination, both the procoagulant and platelet-agglutinating activities of Factor VIII became bound to the platelet surface.

\section{INTRODUCTION}

Factor VIII is a high molecular weight glycoprotein complex with at least two activities. It is an essential component of the intrinsic pathway of blood coagulation (antihemophilic factor activity) and is required for the normal hemostatic function of the blood platelets (von Willebrand's factor activity).

Hemophiliacs treated with bovine Factor VIII preparations develop thrombocytopenia (1), presumably because of in vivo platelet aggregation. Early reports

This work has been presented in part to the National Conference on Thrombosis and Hemostasis, American Heart Association, November, 1974.

Received for publication 18 October 1974 and in revised form 14 April 1975. indicated that bovine fibrinogen aggregated human platelets $(2,3)$ but Forbes and Prentice (4) showed that the aggregating activity in bovine cryoprecipitate was eluted from an agarose column with Factor VIII, and not with fibrinogen. Griggs, Cooper, Webster, Wagner, and Brinkhous (5) have reported using 0.25 $\mathrm{M} \mathrm{CaCl}$ to dissociate the coagulant activity of bovine Factor VIII from its platelet-aggregating activity, and have found the aggregating activity to be associated with the high molecular weight fraction. The analogy between the platelet-aggregating activity of bovine Factor VIII and the ability of human Factor VIII to correct the bleeding tendency in von Willebrand's disease (von Willebrand factor activity) is strong, but has not been definitely established.

Aggregation of human platelets by bovine Factor VIII may have some analogy to the role of human Factor VIII in the normal platelet aggregation mechanism. Patients with von Willebrand's disease have long bleeding times and decreased platelet retention in glass bead columns (6). This disease is associated with reduced Factor VIII procoagulant activity and a decrease in the amount of circulating Factor VIII protein, determined immunologically (7).

The antibiotic ristocetin causes platelet aggregation in normal platelet-rich plasma (PRP). ${ }^{1}$ Platelet aggregation induced by ristocetin is generally defective in von Willebrand's disease (8). Platelets washed to remove Factor VIII are not aggregated by ristocetin. Aggregation can be restored by the addition of purified human Factor VIII (9), but not by other plasma components. Platelets from patients with Bernard-Soulier syndrome are not aggregated by ristocetin (10) or by bovine Factor VIII (11).

${ }^{1}$ Abbreviations used in this paper: DTNB, 5,5'-dithiobis(2-nitrobenzoic acid); 5HT, 5-hydroxytryptamine; MCV, mean cell volume; NEM, $N$-ethylmaleimide; PHAP, phytohemagglutinin P; PHMB, p-hydroxymercuribenzoic acid (equivalent to $p$-chloromercuribenzoic acid); PHMBS, $p$ hydroxymercuriphenyl sulfonate; PRP, platelet-rich plasma. 
In this paper we use the term "aggregation" to mean clumping of platelets in which the platelets actively participate. Aggregation is blocked by metabolic inhibitors. "Agglutination" refers to a passive clumping, as in antibody-induced agglutination.

We report the effects of purified bovine Factor VIII on human platelets both in PRP and in suspensions of platelets treated with formalin. The effects of several inhibitors and chemical modifications of the Factor VIII were studied to determine the molecular basis for the interaction between Factor VIII and platelets.

\section{METHODS}

Buffers. Tris-saline buffer was $0.01 \mathrm{M}$ Tris- $\mathrm{HCl}-0.15 \mathrm{M}$ $\mathrm{NaCl}, \mathrm{pH}$ 7.4. Phosphate-saline buffer was $0.01 \mathrm{M}$ sodium phosphate buffer-0.15 M NaCl, pH 6.5 .

Platelets. Blood was collected by venipuncture into oneninth vol of $3.8 \%$ sodium citrate. PRP was prepared by centrifugation at $250 \mathrm{~g}$ for $10 \mathrm{~min}$ at room temperature. PRP was used within $6 \mathrm{~h}$ of the time the blood was drawn. Outdated platelet concentrates were a gift from the Penn-Jersey Regional Red Cross Blood Program.

Formalin-treated platelets were prepared by mixing PRP or platelet concentrates with an equal volume of Tris-saline buffer containing $8 \mathrm{mg} / \mathrm{ml}$ formaldehyde (Tris-saline buffer: formalin, $98: 2 \mathrm{vol} / \mathrm{vol}$ ) and stored at $4^{\circ} \mathrm{C}$ until needed. The platelets were then centrifuged at $1,500 \mathrm{~g}$ for $10 \mathrm{~min}$ and resuspended in phosphate-saline buffer. Centrifugation and resuspension were repeated twice. Platelets were finally suspended to approximately $8 \times 10^{\circ}$ platelets $/ \mathrm{ml}$ in phosphate-saline buffer, then diluted $1: 18$ in Tris-saline buffer for aggregation studies. These formalin-washed platelets could be stored at $0^{\circ} \mathrm{C}$ for at least a week without losing their ability to be agglutinated by bovine Factor VIII.

Platelet aggregation was studied in the apparatus described by Mills and Roberts (12), and in a Payton aggregometer (Payton Instrument Co., Buffalo, N. Y.) modified to increase the stirring speed to $1,500-1,600 \mathrm{rpm}$, so that comparable aggregation traces could be obtained from both instruments. Platelet mean cell volume was determined in a Coulter Channelyzer (Coulter Electronics, Inc., Hialeah, Fla.), calibrated with latex particles.

Factor VIII. Bovine Factor VIII, prepared by the method of Schmer, Kirby, Teller, and Davie (13), was 9095\% homogeneous by acrylamide gel electrophoresis in sodium dodecyl sulfate. Human Factor VIII, prepared by the method of Legaz, Schmer, Counts, and Davie (14) was also $90-95 \%$ homogeneous. Factor VIII activity was measured by a modification of the kaolin-activated one-stage partial thromboplastin time (15). Samples of purified Factor VIII were generally diluted 100 - to 1,000 -fold in Trissaline buffer before assay.

Protein concentrations were determined by the method of Lowry, Rosebrough, Farr, and Randall (16) with bovine serum albumin as standard. Platelet protein was determined after platelets were lysed in $1 \mathrm{~N} \mathrm{NaOH}-1 \%$ Triton $\mathrm{X}-100$, then further diluted in $0.1 \mathrm{~N} \mathrm{NaOH}$.

Platelet release reaction. Release of 5-hydroxytryptamine (5HT) was measured in citrated PRP preincubated with $0.5 \mu \mathrm{M} \quad\left[3-{ }^{14} \mathrm{C}\right] 5 \mathrm{HT}$ creatinine sulfate $(55 \mathrm{Ci} / \mathrm{mol}$, Amersham/Searle Corp., Arlington Heights, Ill.) for $30 \mathrm{~min}$ at $37^{\circ} \mathrm{C}$. After this incubation, approximately $85 \%$ of the radioactivity had been taken up by the platelets. For mea- surement of release, $0.8 \mathrm{ml}$ of the labeled PRP was put in an aggregometer cuvette and stirred. Appropriate additions were made and the aggregation response followed. After aggregation was completed, EDTA was added to those samples which did not already contain EDTA, and the PRP was centrifuged at 12,000 rpm for $30 \mathrm{~s}$ in an Eppendorf micro-centrifuge fitted with a swing-out rotor. A 0.1$\mathrm{ml}$ aliquot of each supernate was added to $0.5 \mathrm{ml}$ of $1 \%$ Triton X-100 in a 6-ml scintillation vial. $5 \mathrm{ml}$ of dioxanenaphthalene-butyl phenylbiphenyloxadiazole scintillant (17) was added and the samples were counted in an Intertechnique model SL40 liquid scintillation counter (Intertechnique, Dover, N. J.).

Adsorption of fibrinogen to platelets. Human fibrinogen was prepared by the method of Blombäck and Blombäck (18). Fraction I-4 material was labeled with ${ }^{125} \mathrm{I}$ by the iodine monochloride method (19). The labeled fibrinogen (65\% clottable) was diluted with fresh plasma and chromatographed on a column of Sephadex G-25 (Pharmacia Fine Chemicals, Piscataway, N. J.) to remove ${ }^{125}$ I not bound to protein. This labeled fibrinogen (approximately $6 \mu \mathrm{Ci}$ ) was added to $42 \mathrm{ml}$ of fresh PRP. Aliquots $(14 \mathrm{ml})$ were then added to equal volumes of either $(a)$ Tris-saline buffer, (b) Tris-saline buffer containing $10 \mathrm{mM}$ EDTA, or (c) Tris-saline buffer containing $0.8 \%$ formaldehyde. Suspensions $a$ and $b$ were incubated at room temperature for 45 min, then centrifuged at $3,500 \mathrm{rpm}$ for $15 \mathrm{~min}$ at room temperature and resuspended in phosphate-saline buffer (containing $5 \mathrm{mM}$ EDTA for sample $b$ ). Centrifugation and resuspension were repeated twice. Formalin-treated platelets were incubated overnight at $4^{\circ} \mathrm{C}$, then washed in the same way, with phosphate-saline buffer. All washes and the final platelet suspensions were counted in a Nuclear Chicago gamma counter (Nuclear Chicago, Div. of Searle Analytic, Inc., Des Plaines, Ill.). The radioactivity in the thrice-washed platelets was used as an estimate of bound fibrinogen.

Thiol groups. Available free thiol groups on Factor VIII were determined with 5,5'-dithiobis-(2-nitrobenzoic acid) (DTNB) by the method of Ellman (20). Factor VIII was dialyzed against $0.01 \mathrm{M}$ sodium phosphate- $0.15 \mathrm{M} \mathrm{NaCl}$ $\mathrm{pH}$ 8.0. An excess of DTNB was added, and free thiol groups were estimated by the increase in absorbance at 412 $\mathrm{nm}$, assuming a molar extinction coefficient for the free nitrothiophenolate anion of 14,140 (21). Incubations of Factor VIII with DTNB contained a more than 100 -fold excess of DTNB.

Sialic acid. Neuraminidase (Type VI, from Clostrium perfringens) was purified by chromatography on Biorex-70 (Biorad Laboratories, Richmond, Calif.) to remove proteolytic activity (22). The specific activity of the purified neuraminidase was $2.5 \mathrm{U} / \mathrm{mg}$ when assayed on bovine submaxillary mucin at $\mathrm{pH} 5.0$ and $37^{\circ} \mathrm{C}$. Platelets and Factor VIII were incubated with neuraminidase at room temperature in phosphate-saline buffer. Total sialic acid content (calculated as $N$-acetylneuraminic acid) of Factor VIII was determined after hydrolysis with $0.095 \mathrm{~N} \mathrm{H}_{2} \mathrm{SO}_{4}$ at $80^{\circ} \mathrm{C}$ for $75 \mathrm{~min}$. Total platelet sialic acid was determined after hydrolysis with $0.15 \mathrm{~N} \mathrm{H}_{2} \mathrm{SO}_{4}$ at $80^{\circ} \mathrm{C}$ for $50 \mathrm{~min}$. Released sialic acid was measured by the method of Warren (23), with $N$-acetylneuraminic acid as a standard.

Reagents. The following reagents were obtained from Sigma Chemical Co. (St. Louis, Mo.) : ADP, bovine submaxillary mucin, 2-deoxy-D-glucose, collagen (bovine achilles tendon, type I), dextran sulfate $\left(\mathrm{mol} \mathrm{wt}=2 \times 10^{6}\right)$, DTNB, heparin (sodium salt, from hog intestinal mucosa, $175 \mathrm{U} /$ $\mathrm{mg}$ ), histone (calf thymus, type IIA), $N$-acetylneuraminic 
acid, neuraminidase (Type VI), $N$-ethylmaleimide (NEM), $p$-hydroxymercuribenzoic acid (PHMB), $p$-hydroxymercuriphenylsulfonic acid (PHMBS), polylysine (mol wt, 85,000 and 195,000), and Tris base. Antimycin A was obtained from Calbiochem (San Diego, Calif.). Triton X-100 was obtained from Beckman Instruments, Inc. (Fullerton, Calif.). General laboratory reagents were obtained from Fisher Scientific Co. (Pittsburgh, Pa.). Bovine thrombin (topical) was obtained from Parke, Davis \& Company (Detroit, Mich.). Phytohemagglutinin $\mathrm{P}$ was from Difco Laboratories (Detroit, Mich.). Collagen in $0.1 \%$ acetic acid was prepared by the method of Day and Holmsen (24). Heparin was covalently bound to agarose (Biogel A $1.5 \mathrm{~m}$, Bio-Rad Laboratories, Richmond, Calif.) with cyanogen bromide (25).

\section{RESULTS}

Platelet aggregation by bovine Factor VIII. The traces in Fig. 1 compare the effect of thrombin and bovine factor VIII on platelets in fresh citrated PRP. At low concentrations of Factor VIII $(2 \mu \mathrm{g} / \mathrm{ml})$, two phases of clumping were observed, the second of which was associated with the release of $\left[{ }^{14} \mathrm{C}\right] 5 \mathrm{HT}$ from the platelets. Release and the second phase of aggregation were inhibited by EDTA (12.5 mM) or PHMBS (1.25 $\mathrm{mM}$ ), but the first phase was not affected. Concentrations of bovine Factor VIII below $1 \mu \mathrm{g} / \mathrm{ml}$ (not shown) failed to induce the release of $5 \mathrm{HT}$ and caused only a small single phase of clumping, which was not inhibited by EDTA or PHMBS.

Most aggregating agents, with the exception of epinephrine, cause a small decrease in the optical transmittance of PRP before aggregation, as the platelets lose their disk shape (26). This effect was not seen at any concentration of bovine Factor VIII.

Higher concentrations of bovine Factor VIII $(5 \mu \mathrm{g} /$ ml) caused more extensive clumping, with a second phase that was not prevented by EDTA or PHMBS. Release of platelet constituents was not required for this second phase. At an even higher concentration of Factor VIII $(14 \mu \mathrm{g} / \mathrm{ml})$, a massive single phase of clumping occurred. EDTA had little or no effect on clumping in the presence of these very high Factor VIII concentrations.

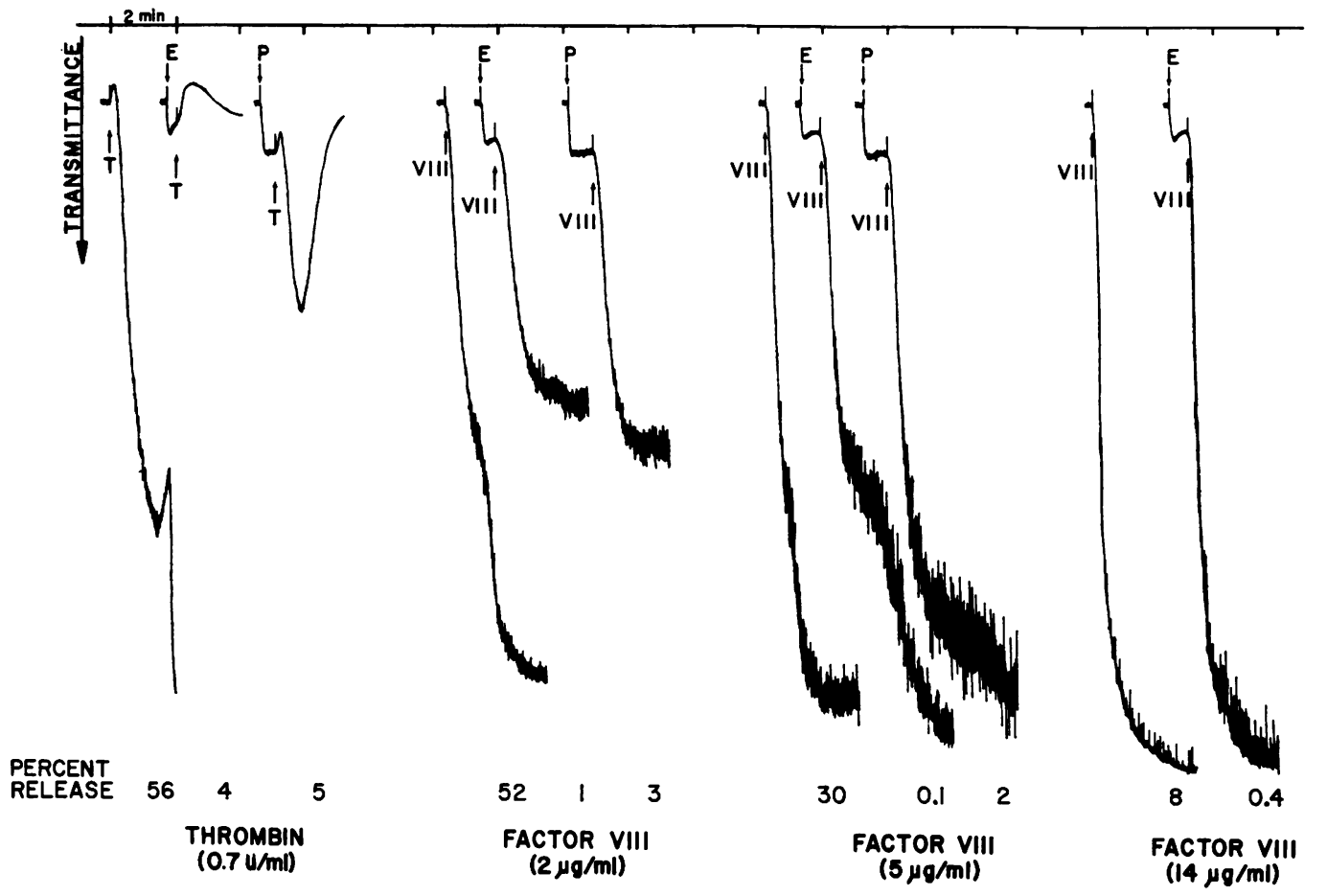

FIGURE 1 Platelet aggregation by thrombin and bovine Factor VIII. Platelets in citrated PRP were labeled by preincubation with $\left[3-{ }^{14} \mathrm{C}\right] 5 \mathrm{HT}$. The PRP was stirred at $37^{\circ} \mathrm{C}$ and EDTA or PHMBS added where indicated ( $E$ and $P$ ) to give $12.5 \mathrm{mM}$ and $1.25 \mathrm{mM}$, respectively. The immediate increase in transmittance upon addition of EDTA or PHMBS is due to dilution of the PRP. Aggregation was initiated by the addition of thrombin ( $T$ ) or bovine Factor VIII (VIII) at the final concentration indicated. After aggregation was complete ( $2 \mathrm{~min}$ for thrombin-induced, $4 \mathrm{~min}$ for Factor VIII-induced aggregation), EDTA was added to each sample that did not already contain EDTA and the samples were centrifuged. The radioactivity in each of the supernates was determined by scintillation counting. The calculated percent of $5 \mathrm{HT}$ release is given below each tracing. 


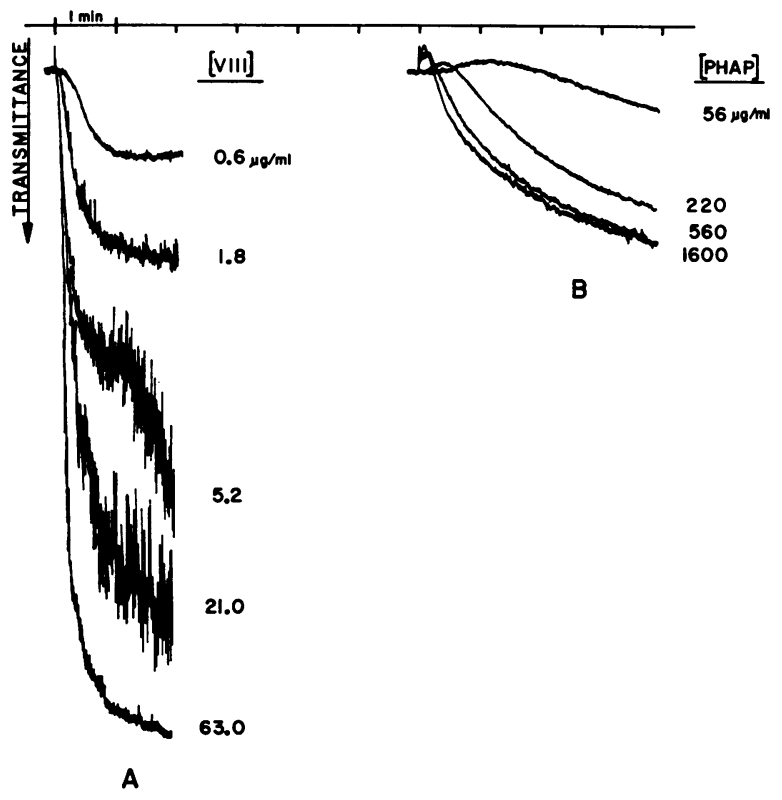

Figure 2 Effects of Factor VIII and PHAP on platelets in PRP. EDTA was added to citrated PRP to a final concentration of $5 \mathrm{mM}$. Factor VIII (A), or PHAP (B) was added to give the indicated concentrations.
Increasing the concentration of bovine Factor VIII caused a reduction in the amount of $5 \mathrm{HT}$ released, and this reduced degree of release was further inhibited by EDTA and by PHMBS. With the highest concentration of bovine Factor VIII, there was very little release, although clumping was rapid and extensive. All of the platelets were present in a few large aggregates, in contrast to the numerous small aggregates formed at lower concentrations. This gave rise to a characteristic "spiky" appearance of the trace, the spikes being caused as the one or two large aggregates passed through the light path of the aggregometer.

The formation of these characteristic large aggregates by bovine Factor VIII we have termed "superaggregation". This phenomenon is not blocked by 12.5 $\mathrm{mM}$ EDTA or $1.25 \mathrm{mM}$ PHMBS and does not require the platelet release reaction to occur. The only other agent with which we have seen this characteristic aggregation response in EDTA-treated platelets is ristocetin in the presence of human Factor VIII.

Comparison of Factor VIII-induced and lectin-induced aggregation. Phytohemagglutinin $\mathrm{P}$ (PHAP) is a plant lectin that binds to the $N$-acetylgalactosamine residues of certain glycoproteins. PHAP causes platelet agglutination (27) and can induce the release reaction

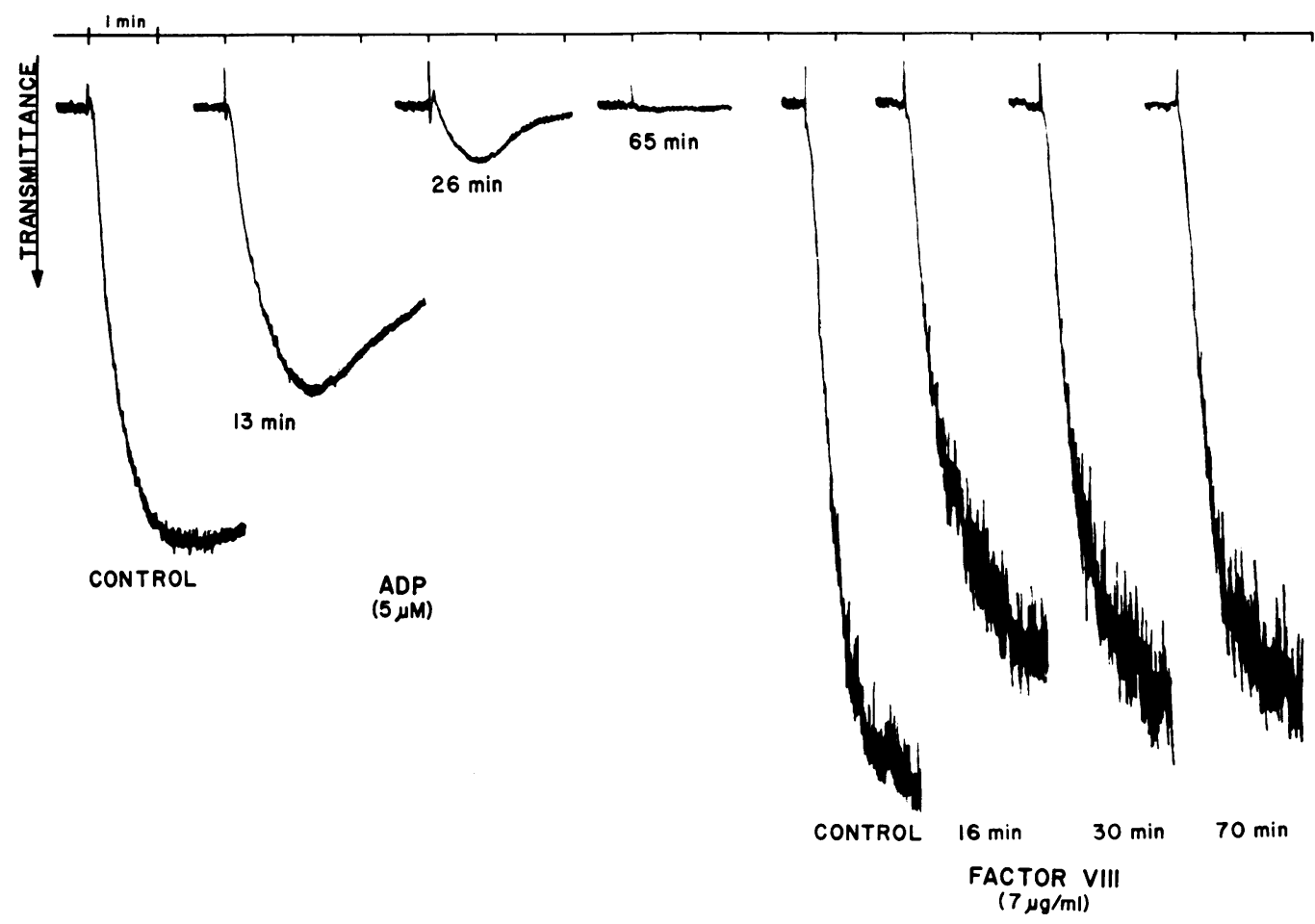

FIGURE 3 Effects of metabolic inhibitors on the platelet response to ADP and Factor VIII. PRP was incubated with antimycin A $(5 \mu \mathrm{g} / \mathrm{ml})$ and 2-deoxy-D-glucose $(20 \mathrm{mM})$ at $37^{\circ} \mathrm{C}$. At the indicated times, samples were removed and transferred to aggregometer cuvettes, and aggregation was initiated with either ADP $(5 \mu \mathrm{M})$ or bovine Factor VIII $(7 \mu \mathrm{g} / \mathrm{ml})$. 
(28). PHAP, like Factor VIII, caused agglutination in the presence of EDTA (Fig. 2), but there were several differences between the effects of these two agents. Agglutination by PHAP was neither as extensive nor as rapid as the response to Factor VIII (Fig. 2), nor was super-aggregation seen with PHAP.

Both experiments shown in Fig. 2 were done with the same batch of PRP, so the aggregometer traces are directly comparable. Essentially all of the platelets were clumped in all of these traces. The differences in percent transmission after clumping apparently represent differences in the size and structure of the aggregates.

Effects of metabolic inhibitors. Incubation of fresh citrated PRP with antimycin A $(5 \mu \mathrm{g} / \mathrm{ml})$ and 2-deoxy-D-glucose $(20 \mathrm{mM})$ causes a decrease in the metabolic ATP content of platelets (29), which is reflected in a decrease in the adenylate energy charge as determined by the method of Mills (30). We observed that the amount of ATP decreased from about $80 \%$ of the metabolically active pool to less than $30 \%$ within 30 min. As shown in Fig. 3, incubation of platelets with antimycin and deoxyglucose abolished the response to ADP, but the platelets were still clumped by bovine Factor VIII. These results are similar to those obtained by Solum (3), who studied aggregation induced by a preparation of bovine platelet fibrinogen.

The first phase of platelet clumping induced by bovine Factor VIII is an agglutination reaction, as de-

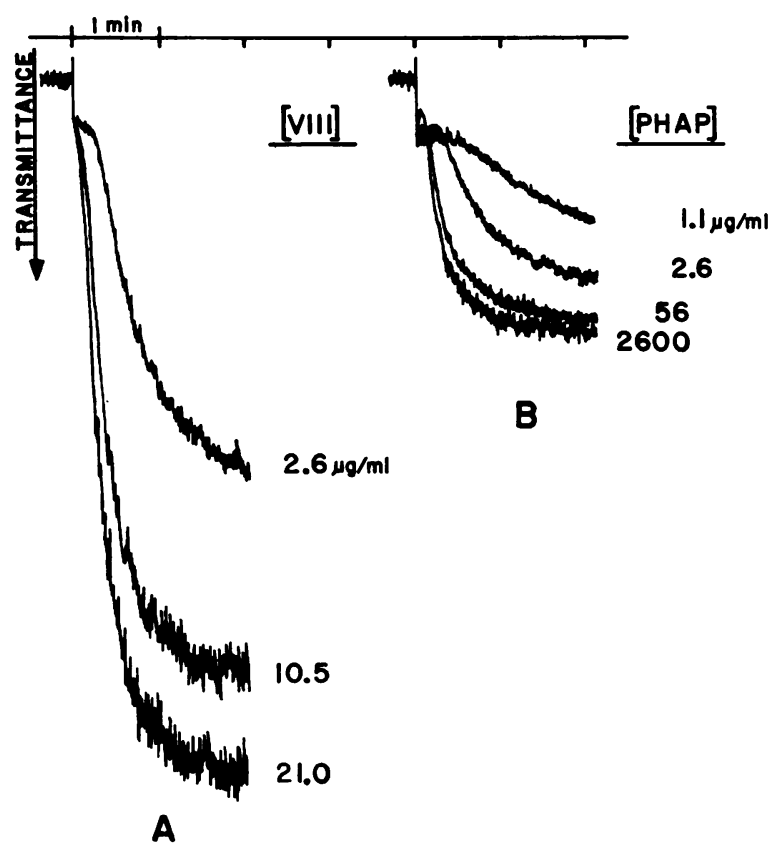

Figure 4 Agglutination by Factor VIII and PHAP. Factor VIII (A), or PHAP (B) was added to formalintreated platelets in Tris-saline buffer to give the indicated concentrations.

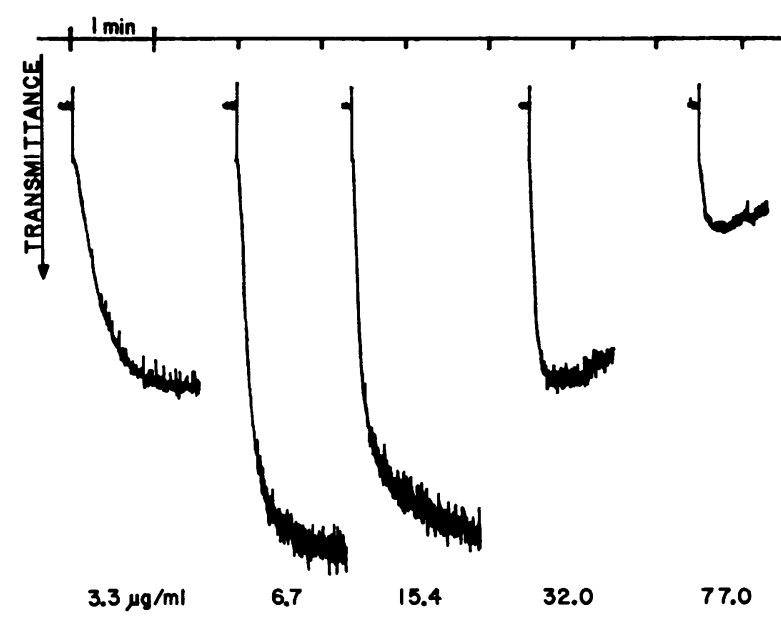

Figure 5 Agglutination by polylysine. Polylysine (mol wt $=195,000$ ) was added to formalin-treated platelets in Tris-saline buffer to give the indicated concentrations.

fined above, since it is not prevented by EDTA, PHMBS, or metabolic inhibitors such as antimycin and deoxyglucose.

Formalin-treated platelets. Since the metabolic integrity of the platelets was apparently not required for agglutination by bovine Factor VIII, experiments were performed with platelets fixed with formalin.

Formalin-treated platelets did not aggregate spontaneously. They were disk-shaped and showed the "swirling" effect in stirred suspensions. Pellets obtained by centrifugation of formalin-treated platelets were more easily resuspended than pellets of untreated platelets.

Formalin-treated platelets were apparently larger. Platelet pellets were bigger, and the mean cell volume (MCV), determined electronically with a Coulter Counter, was increased. The average MCV from five different units of outdated blood bank platelets was $9.9 \pm 0.6 \mu \mathrm{m}^{3}$. After formalin treatment, these same platelets had an average $\mathrm{MCV}$ of $11.7 \pm 0.6 \mu \mathrm{m}^{3}$, a significant difference $(P<0.01)(31)$.

Treatment of platelets with formalin did not cause nonspecific binding of plasma proteins to the platelet surface. When radioactive fibrinogen was added to PRP and the platelets were washed by centrifugation and resuspension, all but $0.015 \%$ of the radioactivity was removed after three washes. The presence of EDTA did not significantly affect this minimal level of binding. Overnight storage in the presence of formalin caused only a slight increase (to $0.04 \%$ ) in the residual radioactive fibrinogen, which still represented less than $0.2 \%$ of the total platelet protein.

Agglutination of formalin-treated platelets. Suspensions of formalin-treated platelets did not respond to ADP, collagen, or thrombin but were aggluti-

Interaction of Factor VIII with Platelets 495 


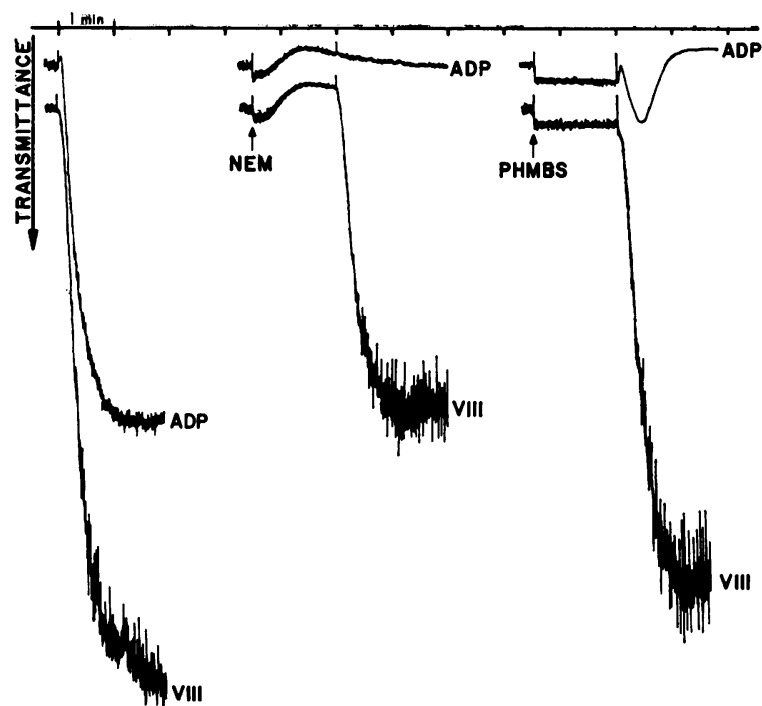

FIgURE 6 Effects of NEM and PHMBS on aggregation in PRP. NEM or PHMBS was added to citrated PRP to a final concentration of $2.5 \mathrm{mM}$. Aggregation was initiated with either ADP $(5 \mu \mathrm{M})$ or bovine Factor VIII $(7 \mu \mathrm{g} / \mathrm{ml})$.

nated by bovine Factor VIII (Fig. 4A). Increasing the Factor VIII concentration caused an increase in both the rate and the extent of agglutination, and shortened the lag phase seen at low concentrations. The procoagulant activity of the Factor VIII preparation was not essential for platelet agglutination, since all procoagulant activity could be destroyed by prolonged thrombin treatment without inhibition of the agglutinating activity.

Although high concentrations of bovine Factor VIII caused extensive agglutination, the aggregates were discrete and qualitatively different from the superaggregates seen in PRP or in suspensions of washed platelets not treated with formalin. The amount of Factor VIII necessary for optimal agglutination of formalin-treated platelets was dependent on the platelet concentration and varied with different batches of platelets.

Much lower concentrations of PHAP were required to induce agglutination in formalin-treated platelets than in PRP, suggesting that plasma proteins act as haptene inhibitors in the PRP system. Even at very high concentrations of PHAP, however, the extent of agglutination was not as great as with Factor VIII (Fig. 4B).

Formalin-treated platelets are also agglutinated by polylysine (32). Fig. 5 shows that low concentrations of highly polymerized polylysine ( $\mathrm{mol} \mathrm{wt}=195$,000 ) caused rapid agglutination. Higher concentrations were not as effective. Similar observations were made with histone and with polylysine of mol wt 85,000.
Polylysines of lower molecular weight caused microscopic agglutination, but not enough to alter the transmittance of the suspensions in the aggregometer. Neither histone nor polylysine caused super-aggregation in PRP.

Role of free thiol groups. Thiol groups on the platelet surface are essential for platelet aggregation by ADP and thrombin (33). Fig. 6 shows that $2.5 \mathrm{mM}$ NEM or PHMBS, both of which react with thiol groups, blocked the aggregation of platelets by ADP, without blocking the agglutination induced by bovine Factor VIII. PHMB (2 $\mathrm{mM})$, however, was able to block both ADP and Factor VIII-induced aggregation. A similar action of PHMB on ristocetin-induced agglutination had been reported by Kattlove and Gomez (34).

Pretreatment of Factor VIII for up to $80 \mathrm{~min}$ with NEM or PHMBS had no effect on its platelet-agglutinating activity and caused only a slight decrease in its procoagulant activity (Table I). The lack of effect of these reagents on Factor VIII is to be expected since Legaz et al. (14) reported that there are no free thiol

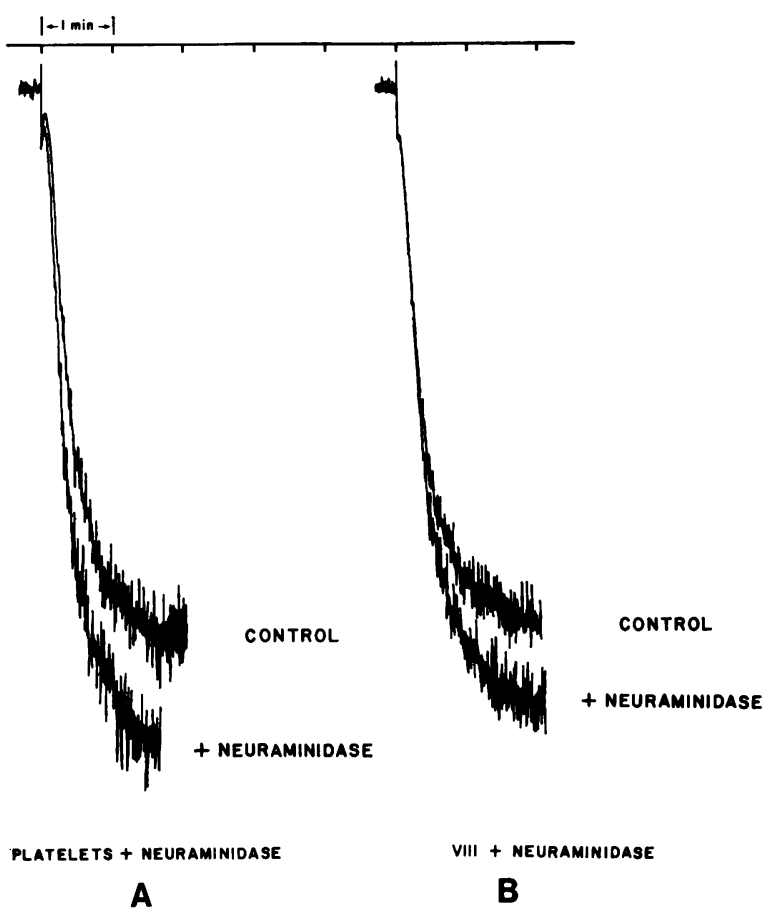

Figure 7 Action of neuraminidase. (A) Formalin-treated platelets in phosphate-saline buffer were incubated with $0.033 \mathrm{U} / \mathrm{ml}$ of neuraminidase at room temperature for $140 \mathrm{~min}$. The platelets were diluted $1: 16$ in Tris-saline buffer and agglutination was initiated with $7.2 \mu \mathrm{g} / \mathrm{ml}$ Factor VIII. (B) Bovine Factor VIII $(1.1 \mathrm{mg} / \mathrm{ml})$ was incubated with $0.016 \mathrm{U} / \mathrm{ml}$ of neuraminidase at room temperature for $1 \mathrm{~h} .4 .5 \mu \mathrm{g} / \mathrm{ml}$ of Factor VIII was used to initiate agglutination of formalin-treated platelets. Controls were incubated in the absence of neuraminidase. 
TABLE 1

Treatment of Factor VIII with Thiol Blocking Reagents

\begin{tabular}{|c|c|c|c|c|c|c|}
\hline \multirow[b]{2}{*}{ Incubation times } & \multicolumn{2}{|c|}{$\begin{array}{l}\text { Relative extent } \\
\text { agglutination }\end{array}$} & \multicolumn{4}{|c|}{ Average clotting time } \\
\hline & $11 \mathrm{~min}$ & $80 \mathrm{~min}$ & $10 \mathrm{~min}$ & $20 \mathrm{~min}$ & $45 \mathrm{~min}$ & $80 \mathrm{~min}$ \\
\hline & & & & & & \\
\hline Factor VIII + buffer & 1.00 & 0.95 & 72.4 & 74.0 & 71.4 & 72.2 \\
\hline Factor VIII + PHMBS $(10 \mathrm{mM})$ & 1.02 & 1.09 & 79.7 & 81.2 & 75.0 & 82.7 \\
\hline Factor VIII + NEM $(10 \mathrm{mM})$ & 1.05 & 0.94 & 76.2 & 73.8 & 78.9 & 75.2 \\
\hline
\end{tabular}

Factor VIII $(0.4 \mathrm{mg} / \mathrm{ml})$ was mixed with either Tris-saline buffer, NEM, or PHMBS and incubated at $28^{\circ} \mathrm{C}$. After 11 and $80 \mathrm{~min}$ of incubation, $20 \mu \mathrm{l}$ samples were added to $0.6 \mathrm{ml}$ of a suspension of formalintreated platelets. The extent of agglutination of these platelets after $2 \mathrm{~min}$ is reported relative to the control sample. Also, at the indicated times, samples were diluted 1:150 and assayed for Factor VIII procoagulant activity: Reported clotting times represent averages of duplicate samples. Under the conditions of this assay, a 10-s difference in clotting times would represent approximately a twofold difference in Factor VIII procoagulant activity.

groups on bovine Factor VIII. In support of this, we found less than $1 \mathrm{~mol}$ of available $\mathrm{SH} / 600,000 \mathrm{~g}$ of protein when purified Factor VIII $(0.7 \mathrm{mg} / \mathrm{ml})$ was treated with $0.16 \mathrm{M} \mathrm{DTNB}$.

Action of neuraminidase. The total sialic acid content of formalin-treated platelets was $8.4 \mu \mathrm{g} / \mathrm{mg}$ platelet protein. This confirms reported values of 8.4 $\mu \mathrm{g} / \mathrm{mg}$ (35) and $10 \mu \mathrm{g} / \mathrm{mg}$ (36) for washed platelets. Incubation of formalin-treated platelets with purified neuraminidase caused rapid release of $60 \%$ of the sialic acid. The remaining residues were not removed, even after prolonged incubation. Neuraminidase treatment did not cause spontaneous aggregation of formalin-treated platelets, in contrast to its effect on washed native platelets. Removal of $60 \%$ of the sialic acid residues from the formalin-washed platelets did not inhibit agglutination by bovine Factor VIII (Fig. 7A). The rate of agglutination was, in fact, slightly increased after this treatment, perhaps because of a consequent decrease in net negative charge on the platelet surface.

Acid hydrolysis of purified bovine Factor VIII indicated a total sialic acid content of $24 \mu \mathrm{g} / \mathrm{mg}$ protein, in agreement with the value of $21 \mu \mathrm{g} / \mathrm{mg}$ found by Schmer et al. (13). Purified neuraminidase released $53 \%$ of the total sialic acid from Factor VIII without altering its coagulant activity. Neuraminidase treatment of Factor VIII also caused no change in its ability to agglutinate formalin-treated platelets (Fig. 7B), or to agglutinate native platelets in PRP.

Vermylen, Donati, de Gaetano, and Verstraete (37) observed that human Factor VIII, treated with $1 \mathrm{U} / \mathrm{ml}$ of a commercial neuraminidase preparation, developed the ability to aggregate human platelets in PRP directly, without the addition of ristocetin. We have observed this phenomenon, under the same conditions.
However, this aggregation was blocked by the addition of $5 \mathrm{mM}$ EDTA to the PRP, suggesting a different

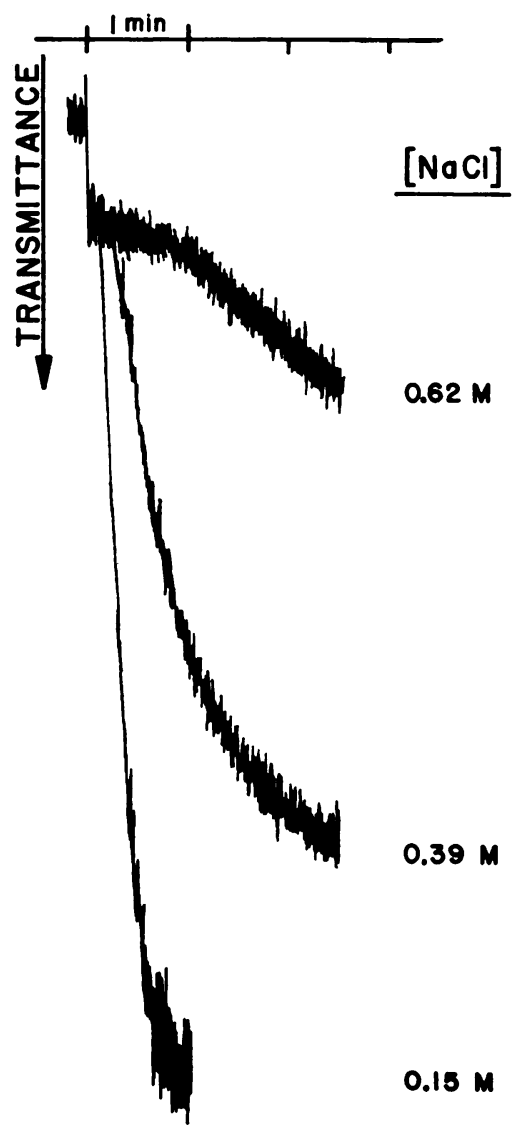

FIGURE 8 Inhibition of Factor VIII-induced agglutination by high salt concentrations. Agglutination was initiated by the addition of Factor VIII $(10 \mu \mathrm{g} / \mathrm{ml})$ to formalintreated platelets in $0.01 \mathrm{M}$ Tris buffer, $\mathrm{pH} 7.4$, containing $0.15,0.39$, or $0.62 \mathrm{M} \mathrm{NaCl}$.

Interaction of Factor VIII with Platelets 497 

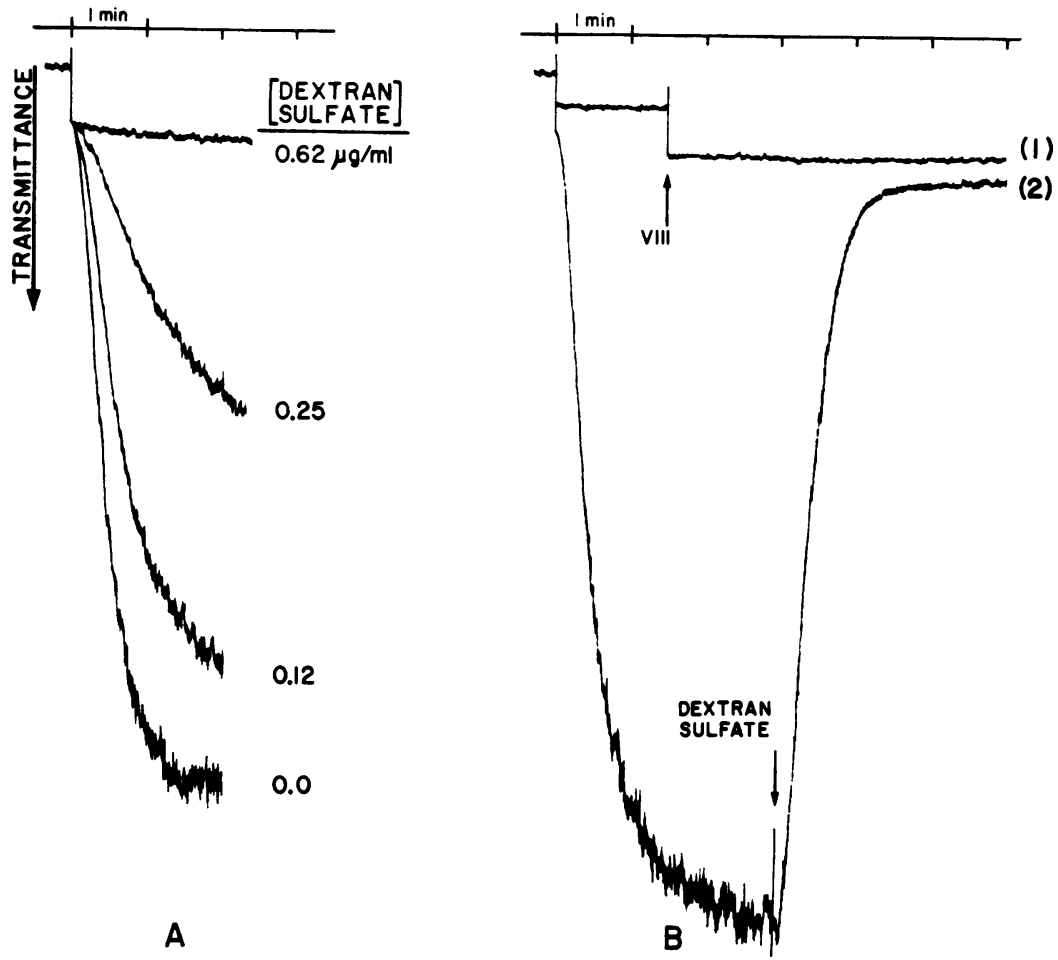

FIGURE 9 Inhibition and reversal of Factor VIII-induced agglutination by dextran sulfate. (A) Dextran sulfate was added to formalin-treated platelets in Tris-saline buffer to give $0.12,0.25$, or $0.62 \mu \mathrm{g} / \mathrm{ml}$. Agglutination was initiated with $7.6 \mu \mathrm{g} / \mathrm{ml}$ of Factor VIII. (B) (1) Dextran sulfate $(1.2 \mu \mathrm{g} / \mathrm{ml})$ was added to formalin-treated platelets, followed by addition of Factor VIII $(7.6 \mu \mathrm{g} / \mathrm{ml})$. (2) Factor VIII $(7.6 \mu \mathrm{g} / \mathrm{ml})$ was added to platelets, followed by addition of dextran sulfate $(1.2 \mu \mathrm{g} / \mathrm{ml})$.

mechanism from the action of bovine Factor VIII. When purified human Factor VIII $(0.2 \mathrm{mg} / \mathrm{ml})$ was treated with $0.016 \mathrm{U} / \mathrm{ml}$ of purified neuraminidase for 2 $\mathrm{h}$ at $37^{\circ} \mathrm{C}$, we did not observe the development of any agglutinating activity toward formalin-treated platelets. Sufficient homogenous human Factor VIII was not available for measurement of released sialic acid, but under similar conditions maximal release of sialic acid from bovine Factor VIII was achieved.

Role of charged groups. The primary interaction between bovine Factor VIII and human platelets may be mediated by charged groups. High sodium chloride concentrations, which interfere with electrostatic interactions, inhibited the agglutination induced by Factor VIII (Fig. 8). Addition of sodium chloride to formalin-washed platelets already agglutinated by Factor VIII caused reversal of the agglutination.

Negatively-charged polymers can inhibit platelet agglutination induced by bovine Factor VIII. Low concentrations $(<1 \mu \mathrm{g} / \mathrm{ml})$ of dextran sulfate completely blocked Factor VIII-induced agglutination (Fig. 9A). Dextran sulfate also inhibited agglutination by polylysine and histone. Higher concentrations of Factor
VIII could overcome the inhibition caused by dextran sulfate, resulting in complete agglutination. Addition of dextran sulfate to formalin-treated platelets agglutinated by Factor VIII completely reversed the agglutination (Fig. 9B).

Very similar effects were seen with heparin, except that concentrations in the range of $0.1-1.0 \mathrm{mg} / \mathrm{ml}$ were required for complete inhibition of agglutination. However, amino groups on heparin give it a lower net charge density than dextran sulfate. Also, the molecular weight of heparin is considerably lower than that of the dextran sulfate used.

The presence of amino groups on heparin allows it to be linked to agarose by the cyanogen bromide method (38). Bovine Factor VIII was passed through a column of heparin-agarose without losing either its procoagulant or platelet-agglutinating activities. This suggests that heparin does not bind strongly to Factor VIII.

Binding of Factor VIII to formalin-treated platelets. Agglutination of platelets by bovine Factor VIII involves a direct binding of the Factor VIII to platelets, as demonstrated in the experiment described in Fig. 10. When platelets were added to a solution of 
TABLE II

Adsorption of Factor VIII to Platelets

\begin{tabular}{|c|c|c|c|c|c|c|c|}
\hline \multirow[b]{2}{*}{ Sample } & \multicolumn{4}{|c|}{ Additions } & \multirow{2}{*}{$\begin{array}{l}\text { Average } \\
\text { clotting } \\
\text { time }\end{array}$} & \multirow[b]{2}{*}{$\begin{array}{l}\text { Coagulant } \\
\text { activity }\end{array}$} & \multirow[b]{2}{*}{$\begin{array}{l}\text { Agglutinating } \\
\text { activity }\end{array}$} \\
\hline & Buffer & $\begin{array}{l}\text { Dextran } \\
\text { sulfate }\end{array}$ & Platelets & Factor VIII & & & \\
\hline & & & & & $s$ & $\%$ & $\%$ \\
\hline 1 & $0.900 \mathrm{ml}$ & - & - & $0.03 \mathrm{ml}$ & 75.5 & 100 & 100 \\
\hline 2 & $0.825 \mathrm{ml}$ & - & $0.075 \mathrm{ml}$ & $0.03 \mathrm{ml}$ & 82.3 & 69 & 42 \\
\hline 3 & - & $0.900 \mathrm{ml}$ & - & $0.03 \mathrm{ml}$ & 72.6 & 115 & - \\
\hline 4 & - & $0.825 \mathrm{ml}$ & $0.075 \mathrm{ml}$ & $0.03 \mathrm{ml}$ & 74.0 & 108 & - \\
\hline 5 & \multicolumn{4}{|c|}{ Eluate from platelet pellet of sample 2} & 75.9 & 11 & - \\
\hline 6 & \multicolumn{4}{|c|}{ Eluate from platelet pellet of sample 4} & 87.8 & 5.6 & - \\
\hline
\end{tabular}

Tris-saline buffer, dextran sulfate $(1 \mu \mathrm{g} / \mathrm{ml}$ in Tris-saline buffer $)$, formalin-treated platelets $\left(6.2 \times 10^{9} \mathrm{ml}\right)$ and bovine Factor VIII $(1.2 \mathrm{mg} / \mathrm{ml})$ were added to siliconized aggregometer cuvettes. Samples were stirred at $37^{\circ} \mathrm{C}$ for $5 \mathrm{~min}$, then centrifuged at $12,000 \mathrm{rpm}$ for $2 \mathrm{~min}$. The supernates were diluted $1: 3$ in Tris-saline buffer for assay of coagulant activity. Aliquots $(0.6 \mathrm{ml})$ of the supernates were added to aggregometer cuvettes and $50 \mu \mathrm{l}$ of formalin-treated platelets added for estimation of the platelet-agglutinating activity remaining in the supernates. The original platelet pellets from samples 2 and 4 were resuspended in $0.3 \mathrm{ml}$ Tris-saline buffer containing $1 \mu \mathrm{g} / \mathrm{ml}$ of dextran sulfate, incubated for at least $\frac{1}{2} \mathrm{~h}$ at room temperature, and then centrifuged. These supernates were assayed for coagulant activity in quadruplicate. The total coagulant and agglutinating activities in sample 1 were defined as $100 \%$; results for other samples have been corrected for dilution.

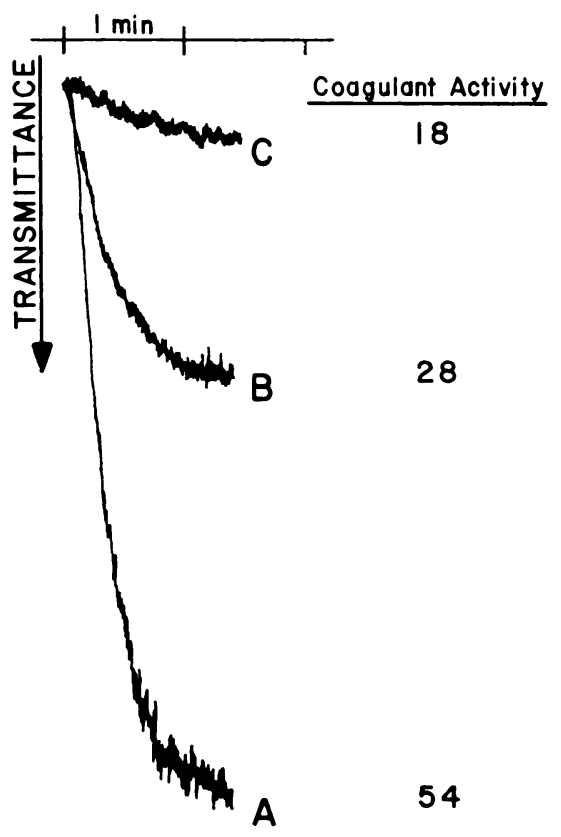

FIGURE 10 Binding to Factor VIII to formalin-treated platelets. (A) $50 \mu \mathrm{l}$ of platelet suspension (approximately $10^{10}$ cells $\left./ \mathrm{ml}\right)$ was added to $0.75 \mathrm{ml}$ Factor VIII $(8 \mu \mathrm{g} / \mathrm{ml})$. After agglutination was completed, the suspension was centrifuged and a sample of the supernate was diluted $1: 3$ and assayed for Factor VIII coagulant activity. (B) 50 $\mu \mathrm{l}$ of platelet suspension was added to the supernate from part A. The sample was centrifuged after agglutination, and the supernate assayed for Factor VIII (C) $50 \mu 1$ of platelet suspension was added to the supernate from part B. The sample was centrifuged after agglutination and the supernate assayed for Factor VIII. Coagulant activity in the supernates is given as percent of initial untreated Factor VIII activity.
Factor VIII, the supernate that remained after agglutination contained only 54\% of the initial Factor VIII coagulant activity (trace A). It was apparent that platelet-agglutinating activity was also removed from the supernate, because when more platelets were added to the supernate (trace B), agglutination occurred at a slower rate and to a decreased extent. After the second adsorption, only $28 \%$ of the initial coagulant activity remained in the supernate, and platelet-agglutinating activity was almost completely gone (trace $\mathrm{C}$ ).

Dextran sulfate $(1 \mu \mathrm{g} / \mathrm{ml})$ does not inhibit the coagulant activity of Factor VIII, but completely blocks its platelet-agglutinating activity. In the presence of dextran sulfate, binding of Factor VIII coagulant activity to formalin-treated platelets was greatly decreased (Table II). When the platelet pellets were resuspended in buffer containing dextran sulfate, significant Factor VIII coagulant activity could be recovered, demonstrating that Factor VIII had been adsorbed rather than inactivated. Significantly less Factor VIII was bound to the platelets in the presence of dextran sulfate than in its absence.

\section{DISCUSSION}

Addition of highly purified bovine Factor VIII to fresh human citrated PRP causes three different types of aggregation phenomena: (a) primary agglutination, (b) secondary aggregation involving the platelet release reaction, and (c) super-aggregation, in which all of the small platelet aggregates are gathered into very large aggregates. These three reactions may occur almost simultaneously under certain conditions. Dif-

Interaction of Factor VIII with Platelets 499 
ferent reagents may be used to block one or more of the reactions selectively.

Primary agglutination. Agglutination of paraformaldehyde-treated platelets by bovine Factor VIII or by ristocetin in the presence of human Factor VIII was first described by Allain and Cooper (32). The use of formalin-treated platelets has several advantages for the investigation of agglutination. Outdated blood bank platelets can be used, and a single batch gives reproducible responses over several days. The responses are not complicated by the occurrence of the release reaction or of super-aggregation, and washing removes the bulk of the plasma proteins without reducing the stability of the suspended platelets.

Thiol groups are necessary for the aggregation of platelets by ADP and thrombin and are readily blocked by NEM and PHMBS (33). Since NEM and PHMBS do not block Factor VIII-induced aggregation, it seems unlikely that the thiol groups involved in ADP- and thrombin-induced aggregation are also involved in Factor VIII-induced aggregation. However, PHMB, a mercurial thiol reagent similar in structure to PHMBS, inhibited agglutination by both bovine Factor VIII and by ristocetin in the presence of human Factor VIII. The latter observation has been reported by Kattlove and Gomez (34).

It is doubtful whether bovine Factor VIII has any reactive thiol groups. If the molecular weight of the subunits of Factor VIII is approximately 150,000 (13), our results with DTNB titration would imply less than one available - $\mathrm{SH}$ group for every four subunits. NEM-reacting groups on bovine Factor VIII, if present, are not involved in either its procoagulant or its platelet-agglutinating activity. Low concentrations (3 $\times 10^{-6} \mathrm{M}$ ) of PHMB had no effect on either of the activities of Factor VIII. High concentrations of PHMBS (10 $\mathrm{mM})$ had no effect on the platelet-agglutinating activity of Factor VIII, and only slightly decreased its procoagulant activity. These observations are in apparent conflict with those of Austen (39), who reported strong inhibition of the procoagulant activity of bovine Factor VIII by several sulfhydryl reagents. In particular, he reported that Factor VIII was $75 \%$ inhibited by $3 \times 10^{-8} \mathrm{M}$ PHMB, although it was less sensitive to higher concentrations.

Platelets from patients with Bernard-Soulier syndrome have less sialic acid than normal (35), and these platelets are not aggregated by bovine fibrinogen (10) or by purified bovine Factor VIII (11), suggesting that sialic acid might play a role in the aggregation of platelets by Factor VIII. However, we found that $60 \%$ of the sialic acid could be removed from formalintreated platelets without inhibiting the agglutination by bovine Factor VIII.
Levy-Toledano, Caen, Halmos, and Mester (40) reported that treatment of bovine plasma with neuraminidase destroyed much of the platelet-agglutinating activity without affecting Factor VIII procoagulant activity. We observed, on the contrary, that neuraminidase treatment of purified bovine Factor VIII could release $53 \%$ of its sialic acid without altering either procoagulant activity or ability to aggregate human platelets.

Agglutination of platelets by bovine Factor VIII involves direct adsorption of Factor VIII onto the platelet surface, since both Factor VIII procoagulant and platelet-agglutinating activities were removed from the solution during agglutination of the platelets (Fig. 10). In agreement with Griggs et al. (5), we observed that relatively more agglutinating activity was bound to the platelet than coagulant activity (Table II). From the amount of Factor VIII removed from the solution, and by assuming a molecular weight of about $2 \times 10^{\circ}$ (13), it can be estimated that the addition of sufficient Factor VIII to cause agglutination of all the platelets is accompanied by the adsorption of approximately 2,000 molecules of Factor VIII/platelet. In contrast, Tollefsen, Feagler, and Majerus (28) reported that the platelet has approximately 300,000 receptors for PHAP, and that approximately $25 \%$ of these must be occupied for half-maximal release of platelet nucleotides.

Several lines of evidence suggest that the interaction between bovine Factor VIII and platelets is an electrostatic one. High molecular weight polycations like polylysine and histone can cause agglutination of formalin-treated platelets in a manner similar to bovine Factor VIII. Negatively charged molecules like dextran sulfate and heparin inhibit the agglutination caused by Factor VIII and by polylysine and can cause disaggregation of platelets agglutinated by Factor VIII. High salt concentrations, which would interfere with electrostatic interactions, also inhibit Factor VIIIinduced agglutination.

The evidence indicates that positively charged groups on Factor VIII are responsible for its interaction with the negatively charged platelet surface. The net charge on Factor VIII at $\mathrm{pH} 7$ is negative, however, as shown by agarose electrophoresis (E. P. Kirby, unpublished results). Perhaps there may be localized regions of positive charge on Factor VIII responsible for its binding to platelets.

Secondary aggregation associated with the release reaction. Addition of bovine Factor VIII to PRP can cause release of platelet $5 \mathrm{HT}$ and induce secondary aggregation associated with this release. EDTA and PHMBS block both the release of 5HT and the secondary aggregation resulting from it. 
Super-aggregation. Super-aggregation is the gathering together of the small platelet aggregates, formed in the early stages of aggregation, into a few very large aggregates. It does not require the release reaction, and is not inhibited by EDTA, PHMBS, or a mixture of antimycin and deoxyglucose.

A certain degree of metabolic integrity in the platelet is required for super-aggregation, since this phenomenon is blocked by treating the platelets with NEM or with formaldehyde. The presence of plasma proteins is not required, since super-aggregation can also be observed upon addition of Factor VIII to washed platelets.

Super-aggregation did not occur with thrombin or with very high concentrations of PHAP, but could be induced by ristocetin in the presence of human Factor VIII. This is apparently a unique characteristic of Factor VIII-induced platelet aggregation and may represent a previously undescribed functional capacity of the platelet.

\section{ACKNOWLEDGMENTS}

We acknowledge the expert technical assistance of Sha May Tang and Robin E. Rosenberg and thank Dr. Donald Macfarlane and Dr. Andrei Budzynski for their helpful discussions and comments on the manuscript.

Cryoprecipitate used in the purification of human Factor VIII, and outdated human platelet concentrates, were gifts from Penn-Jersey Regional Red Cross Blood Program.

This study was supported by Grant-in-Aid 72-754 from the American Heart Association and by National Institutes of Health grants HL-15474 and HL 14214.

\section{REFERENCES}

1. Macfarlane, R. G., R. Biggs, and E. Bidwell. 1954. Bovine antihaemophilic globulin in the treatment of haemophilia. Lancet. 1 : 1316-1319.

2. Caen, J. P., P. A. Castaldi, J. C. Leclerc, S. Inceman, M. J. Larrieu, M. Probst, and J. Bernard. 1966. Congenital bleeding disorders with long bleeding time and normal platelet count. I. Glanzmann's thrombasthenia. (Report of fifteen patients). Am. J. Med. 41: 4-26.

3. Solum, N. O. 1968. Aggregation of human platelets by bovine platelet fibrinogen. Scand. J. Haematol. 5: 474 485.

4. Forbes, C. D., and C. R. M. Prentice. 1973. Aggregation of human platelets by purified porcine and bovine antihaemophilic factor. Nat. New Biol. 241 : 149-150.

5. Griggs, T. R., H. A. Cooper, W. P. Webster, R. H. Wagner, and K. M. Brinkhous. 1973. Plasma aggregating factor (bovine) for human platelets: a marker for study of antihemophilic and von Willebrand factors Proc. Natl. Acad. Sci. U. S. A. 70: 2814-2818.

6. Bouma, B. N., Y. Wiegerinck, J. J. Sixma, J. A. van Mourik, and I. A. Mochtar. 1972. Immunological characterization of anti-haemophilic factor A (Factor VIII) which corrects abnormal platelet retention in von Willebrand's disease. Nat. New Biol. 236: 104-106.

7. Zimmerman, T. S., O. D. Ratnoff, and A. E. Powell 1971. Immunological differentiation of classic hemophilia
(Factor VIII deficiency) and von Willebrand's disease. J. Clin. Invest. 50: 244-254.

8. Howard, M. A., R. J. Sawers, and B. G. Firkin. 1973. Ristocetin: a means of differentiating von Willebrand's disease into two groups. Blood. 41: 687-690.

9. Weiss, H. J., J. Rogers, and H. Brand. 1973. Defective ristocetin-induced platelet aggregation in von Willebrand's disease and its correction by Factor VIII. $J$. Clin. Invest. 52: 2697-2707.

10. Bithell, T. C., S. J. Parekh, and R. R. Strong. 1972. Platelet-function studies in the Bernard-Soulier Syndrome. Ann. N. Y. Acad. Sci. 201: 145-160.

11. Walsh, P. N., D. C. B. Mills, F. I. Pareti, G. J. Stewart, D. E. Macfarlane, M. M. Johnson, and J. J. Egan. 1975. Hereditary giant platelet syndrome: absence of collagen-induced coagulant activity and deficiency of Factor-XI binding to platelets. $\mathrm{Br}$. J. Haematol. 29: 639-655.

12. Mills, D. C. B., and G. C. K. Roberts. 1967. Effects of adrenaline on human blood platelets. J. Physiol. (Lond.). 193: 443-453.

13. Schmer, G., E. P. Kirby, D. C. Teller, and E. W. Davie. 1972. The isolation and characterization of bovine factor VIII (antihemophilic factor). J. Biol. Chem. 247: 2512-2521

14. Legaz, M. E., G. Schmer, R. B. Counts, and E. W. Davie. 1973. Isolation and characterization of human factor VIII (antihemophilic factor). J. Biol. Chem. 248: 3946-3955.

15. Proctor, R. R., and S. I. Rapaport. 1961. The partial thromboplastin time with kaolin. A simple screening test for first stage plasma clotting factor deficiencies. $\mathrm{Am}$. J. Clin. Pathol. 36: 212-219.

16. Lowry, O. H., N. J. Rosebrough, A. L. Farr, and R. J. Randall. 1951. Protein measurement with the Folin phenol reagent. J. Biol. Chem. 193: 265-275.

17. Scales, B. 1967. A new scintillator for liquid scintillation counting. Int. J. Appl. Radiat. Isot. 18: 1-6.

18. Blombäck, B., and M. Blombäck. 1956. Purification of bovine and human fibrinogen. Ark. Kemi. 10: 415-443.

19. McFarlane, A. S. 1958. Efficient trace-labelling of proteins with iodine. Nature (Lond.). 182: 53.

20. Ellman, G. L. 1959. Tissue sulfhydryl groups. Arch. Biochem. Biophys. 82 : 70-77.

21. Collier, H. B. 1973. A note on the molar absorptivity of reduced Ellman's reagent, 3-carboxylate-4-nitrothiophenolate. Anal. Biochem. 56: 310-311.

22. Hatton, M. W. C., and E. Regoeczi. 1973. A simple method for the purification of commercial neuraminidase preparations free from proteases. Biochim. Biophys. Acta. 327: 114-120.

23. Warren, L. 1959. The thiobarbituric acid assay of sialic acids. J. Biol. Chem. 234: 1971-1975.

24. Day, H. J., and H. Holmsen. 1972. Laboratory tests of platelet function. Ann. Clin. Lab. Sci. 2: 63-74.

25. Gentry, P. W., and B. Alexander. 1973. Specific coagulation factor adsorption to insoluble heparin. Biochem. Biophys. Res. Commun. 50: 500-509.

26. O'Brien, J. R. 1965. Effects of adenosine diphosphate and adrenaline on mean platelet shape. Nature (Lond.). 207: 306-307.

27. Majerus, P. W., and G. N. Brodie. 1972. The binding of phytohemagglutinins to human platelet plasma membranes. J. Biol. Chem. 247: 4253-4257.

28. Tollefsen, D. M., J. R. Feagler, and P. W. Majerus. 1974. Induction of the platelet release reaction by phytohemagglutinin. J. Clin. Invest. 53: 211-218.

Interaction of Factor VIII with Platelets 
29. Holmsen, H., C. A. Setkowsky, and H. J. Day. 1974. Effects of antimycin and 2-deoxyglucose on adenine nucleotides in human platelets. Biochem. J. $144: 385-396$.

30. Mills, D. C. B. 1973. Changes in the adenylate energy charge in human blood platelets induced by adenosine diphosphate. Nat. New Biol. 243 : 220-222.

31. Hill, A. B. 1971. Principles of Medical Statistics, Oxford University Press, Inc., New York. 9th Edition. 149.

32. Allain, J. P., and H. A. Cooper. 1974. Aggregation of platelets fixed with paraformaldehyde: a study of platelet membrane receptors. Fed. Proc. 33: 244. (Abstr.)

33. Robinson, C. W., Jr., R. G. Mason, and R. H. Wagner. 1963. Effect of sulfhydryl inhibitors on platelet agglutinability. Proc. Soc. Exp. Biol. Med. 113: 857-861.

34. Kattlove, H. E., and M. H. Gomez. 1975. Studies on the mechanism of ristocetin-induced platelet aggregation. Blood. 45: 91-96.

35. Gröttum, K. A., and N. O. Solum. 1969. Congenital thrombocytopenia with giant platelets: a defect in the platelet membrane. Br. J. Haematol. 16: 277-290.
36. Mester, L., L. Szabados, P-R. Guinebault, J. Caen, and S. Levy-Toledano. 1971. Variations de l'acide sialique plaquettaire dans les thrombopathies constitutionnelles et acquises. C. R. Hebd. Seances Acad. Sci. Ser. D Sci. Nat. 273: 2157-2160.

37. Vermylen, J., M. B. Donati, G. de Gaetano, and M. Verstraete. 1937. Aggregation of human platelets by bovine or human Factor VIII. Role of carbohydrate side chains. Nature (Lond.). 244: 167-168.

38. Porath, J., R. Axén, and S. Ernback. 1967. Chemical coupling of proteins to agarose. Nature (Lond.). 215: 1491-1492.

39. Austen, D. E. G. 1970. Thiol groups in the blood clotting action of Factor VIII. Br. J. Haematol. 19 : 477-484.

40. Levy-Toledano, S., J-P. Caen, T. Halmos, and L. Mester. 1973. Dissociation between human platelet agglomerating activity and Factor VIII procoagulant activity of bovine plasma preparations by chemical treatment. I. Effect of neuraminidase. Pathol. Biol. 21: 60-62. 